\title{
Factors That Influence Participation in Classroom-Based Physical Activity Breaks in Head Start Preschoolers
}

\author{
E. Kipling Webster, Leah E. Robinson, and Danielle D. Wadsworth
}

\begin{abstract}
Background: Activity breaks are an established way physical activity may be incorporated into the preschool day. The purpose of this study was to examine what factors influenced moderate to vigorous physical activity (MVPA) during a teacherimplemented classroom-based activity break $(\mathrm{CBAB})$ in a Head Start population. Methods: Ten-minute CBAB was conducted over 2 days in a quasi-experimental design; 99 preschoolers (mean age 3.80 [0.65] y; 49.5\% male) from a convenience sample participated. Accelerometers measured MVPA, fundamental motor skill competency was assessed using the Test of Gross Motor Development—second edition, and weight classification status used body mass index percentiles. Results: A significant, moderate regression was found $(r=.328, P=.001)$ between fundamental motor skill and MVPA. There was no significant correlation between body mass index percentile and MVPA during the CBAB. In addition, the locomotor subscale was the best predictor for MVPA for children during the $\mathrm{CBAB}(r=.32, \beta=0.82, P<.001)$. Conclusions: $\mathrm{CBAB}$ equally elicited MVPA for normal and overweight preschoolers. Fundamental motor skill competency was associated with MVPA during the CBAB; in particular, locomotor skills were the best predictor for physical activity. Structured activity opportunities that focus on locomotor skills may be a useful integration to prompt more MVPA in a preschool-age population.
\end{abstract}

Keywords: accelerometry, intervention study, kinesiology, obesity

Physical activity in early childhood is a critical aspect of healthy development. ${ }^{1}$ Evidence has shown that physical activity levels and sedentary behaviors track throughout childhood ${ }^{2}$; therefore, integrating appropriate physical activity habits at an early age may promote and sustain future activity. However, research on the physical activity levels of preschool-age children has shown that children are not meeting physical activity recommendations ${ }^{3}$ and tend to be inactive or sedentary for large portions of their day. ${ }^{4,5}$

In preschool-age children, high amounts of inactivity have been associated with an increased risk of being overweight or obese ${ }^{6-9}$ while increased physical activity is associated with a reduced risk of being overweight or obese. ${ }^{10,11}$ Meredith-Jones et $\mathrm{al}^{11}$ tracked children from age 1 to 5 , those who had consistently high levels of physical activity had significantly lower body fat at age 5. Less active preschoolers tend to have a higher body mass index (BMI) than their more active peers ${ }^{12,13}$; conversely, greater participation in physical activity is associated with a healthier body weight. ${ }^{7,13}$ Preschoolers with a higher BMI also tend to be less proficient in fundamental motor skills (FMS). ${ }^{14}$

Fundamental motor skills are gross motor skills considered to be the foundation for more advanced physical movements and are learned during early childhood. ${ }^{15,16}$ Specifically, higher FMS are correlated with higher levels of physical activity ${ }^{17,18}$ and increased engagement in moderate to vigorous physical activity (MVPA) for preschoolers. ${ }^{19,20}$ Based on longitudinal evidence, higher levels of FMS early in life positively influenced physical activity later in life. ${ }^{21-23}$ Research has shown that at-risk children, those from disadvantaged and/or low socioeconomic environments who are more susceptible for poor health and developmental delay, are more

Webster is with the Institute of Public and Preventive Health, Augusta University, Augusta, GA. Robinson is with the Center for Human Growth and Development and the School of Kinesiology, University of Michigan, Ann Arbor, MI. Wadsworth is with the School of Kinesiology, Auburn University, Auburn, AL. Webster (ewebster@augusta.edu) is corresponding author. likely to have lower $\mathrm{FMS}^{20,24,25}$; this highlights a need for more opportunities to develop FMS as they do not naturally emerge. ${ }^{26}$

Childcare centers can be important venues to target and improve children's health, particularly as children spend a large percentage of waking hours in attendance. ${ }^{27}$ In addition, teacherled interventions targeting physical activity at childcare centers could have a significant impact on improving MVPA behaviors in preschool children, ${ }^{28}$ and childcare providers tend to allow more physical activity opportunities. ${ }^{29}$ Preschool-age children are more physically active while attending childcare centers. ${ }^{30}$ However, a previous intervention in a childcare center that increased unstructured, free play time did not increase Latino preschoolers' MVPA levels ${ }^{31}$ highlighting how structured activities may be important for this young population.

Classroom-based activity breaks (CBAB), short bouts (ie, $10 \mathrm{~min}$ ) of structured activity, are a good strategy to help meet the recommended 180 minutes of daily activity for preschoolers. ${ }^{1}$ Research has established that $\mathrm{CBAB}$ are effective for increasing physical activity in preschool-age children. ${ }^{32-34}$ However, at this time, there is no literature investigating influential factors that may contribute to participation in physical activity during these short bouts of activity in the classroom.

Thus, it is imperative to understand which factors may need to be the focal point for future CBAB interventions in preschool-age populations. The purpose of this study is to determine influential factors that are associated with MVPA participation during a $\mathrm{CBAB}$ in an at-risk preschool population. Based on the literature, we hypothesize that (1) children with higher FMS competency would participate in more MVPA and (2) children with higher BMI would participate in less MVPA during these short bouts. Results may highlight how to elicit more physical activity behaviors in an at-risk group of children to potentially increase overall physical activity levels and improve health.

The theoretical framework used for this intervention is the socioecological model, which aims to understand the complex 
interconnections of behavioral changes within an individual and their surroundings. ${ }^{35,36}$ This model suggests that interventions are most effective in implementing change when targeting several levels of influence. Other research in preschool populations has found that utilizing a socioecological framework is an effective way to increase physical activity in preschool-age children by targeting early childcare policies ${ }^{37}$ and by training preschool teachers to adopt an active physical or social environment in the classroom. $^{38}$ This framework has also been utilized to examine sedentary behavior in preschool-age children and how multiple levels of influence work in a synergistic manner to influence a child's activity. ${ }^{39}$ This study aims to examine the relationship between the individual factors of the preschoolers (microsystem) targeted through CBAB conducted by classroom teachers (mesosystem). In addition, potential policy changes were examined by the requirement of $\mathrm{CBAB}$ to be conducted on specific testing days within the childcare center (macrosystem) to determine if they are a feasible option for increasing activity.

\section{Methods}

\section{Participants}

One Head Start preschool center in the southeastern region of the United States participated as a convenience sample in this quasiexperimental study..$^{40}$ This center consisted of 11 preschool classrooms, all of which participated in this project. There was a $71 \%$ consent rate at the preschool center (136 students agreed to participate); 99 preschoolers completed all assessments and were included in the analysis (mean age 3.80 [0.65] y; 49.5\% male). The racial makeup of the sample was $81.8 \%$ African American, 9.1\% European American, 5.1\% Hispanic, and 4.0\% from mixed racial background. Approximately $73 \%$ of the participants were used for the final analysis; dropout resulted from the participant moving prior to data collection $(n=18)$ or did not have a complete set of data for each variable examined $(n=19)$. Prior to data collection, Auburn University Institutional Human Subjects Review Board approval (10-217 MR 1009), and parental consent/ child verbal assent were obtained.

\section{Instrumentation}

Anthropometric Data. Race, birth date, and sex were collected from the parents/preschool center. Height and weight were measured to the nearest $0.1 \mathrm{~cm}$ and pound, respectively, using a portable scale (Seca Floor Scale 769; Seca Corporation, Hanover, MD). Children removed shoes and heavy outerwear for anthropometric measurements. Weight classification status for children was determined using the Centers for Disease Control and Prevention (CDC) sex-specific BMI-for-age normative growth charts. CDC normative growth charts provide, based on the participants' height, weight, age, and sex, a BMI percentile using a nationally representative normative data set. ${ }^{41}$ Children were classified as overweight if their BMI percentile was $\geq 85$ th percentile and obese if their BMI percentile was $\geq 95$ th percentile, according the CDC growth charts.

Physical Activity. Actical accelerometers (Mini-Mitter Co, Inc, Bend, OR), a valid measurement device for preschool-age children, ${ }^{42}$ were used to objectively measure physical activity during the CBAB. Accelerometers were calibrated according to the Actical manual guidelines. The epoch length was set to 15 seconds based on device recommendations for preschool-age children. ${ }^{43}$ Monitors were worn on the right hip, directly above the knee, and secured with an elastic belt. Moderate activity ( $\geq 715$ counts/15 s) and vigorous activity (1411 counts/15 s or greater $)^{42}$ cut points were combined to examine MVPA behaviors. For this analysis, average percentage of time spent in MVPA during the 10-minute CBAB [(MVPA counts per minute/Total break counts per minute) $\times$ 100] was used.

Motor Skill Competency. Children completed the Test of Gross Motor Development—-second edition (TGMD-2). ${ }^{44}$ The TGMD-2 assesses 12 FMS separated into 2 subscales: object control (2-handed striking, throwing, catching, kicking, dribbling, and underhand rolling) and locomotor skills (running, galloping, sliding, leaping, hopping, and horizontal jumping). A trained researcher provided an appropriate skill demonstration, and participants completed one practice and 2 formal trials for each FMS; each FMS were evaluated on 3 to 5 performance criteria. A score of 1 was given for each trial if the performance criterion was performed correctly, and a score of 0 was given if the criterion was incorrectly performed. TGMD-2 raw scores were used for analyses; raw scores range from 0 to 96 . Assessments were video recorded and coded through video analysis. Intrarater reliability (>90\%) was established between 2 researchers prior to coding; both were trained by an expert coder and established over $90 \%$ reliability with the expert.

Procedure. Data collection took place across 2 weeks for each classroom between October 2012 and January 2013. Anthropometric and motor skill competency data were assessed during the first week. Anthropometric measurements were conducted individually in the nurse's office for student privacy. Motor skill competency was collected in the school gymnasium in groups of 3 to 4 children. During the second week, classroom teachers implemented $\mathrm{CBAB}$ on 2 days; teacher training is explained in detail elsewhere. ${ }^{34}$ Each CBAB lasted approximately 10 minutes; breaks were integrated into the daily classroom schedule based on meetings with the classroom teacher and childcare center director. Teachers were provided with 2 structured routines that all classrooms used, and fidelity checks were conducted to ensure that all breaks were conducted for the required amount of time and that assigned activities were completed. Each CBAB included a 1-minute warm-up and 1-minute cooldown; activities included arm circles and trunk twists for a warm-up and deep breathing/stretching along with yoga poses for cooldown activities. Eight minutes of activities that focused on MVPA and FMS were completed between the warm-up and cooldown. These alternated in short, 30 -second bouts and included skills such as marching in place and up-downs (sitting down and touching toes, then standing up and jumping). Pilot work identified these were age-appropriate activities that preschool-age children enjoyed participating in during CBAB. ${ }^{33}$

Accelerometers were placed on the students once they arrived in the classroom and removed prior to the end of the school day. The 2 CBABs were scheduled with the classroom teacher and center director's input. Researchers recorded start and end times for each $\mathrm{CBAB}$, which were used for the analysis.

Data Analysis. Descriptive statistics were generated for the sample (means and SDs) for MVPA activity, BMI, and motor skill competency. MVPA percentage was averaged for the 2 days CBAB were conducted. Initially, MVPA differences were examined between boys and girls to suggest if the sample should be analyzed separately. Two simple linear regressions were conducted to examine the impact motor skill competency (total TGMD raw 
score) and weight classification (BMI percentile) had on MVPA during the $\mathrm{CBAB}$. The assumptions of linearity, normality, multicollinearity, and homoscedasticity were checked and found appropriate for regression analysis. ${ }^{45}$ Finally, an exploratory aim was examined with a backward elimination regression; the independent variables included TGMD-2 locomotor raw score, TGMD-2 object control raw score, and BMI percentile; this aimed to identify each variable's contribution to the dependent variable. All alpha levels were set a priori to .05 .

\section{Results}

\section{MVPA Participation During Activity Breaks}

During the $\mathrm{CBAB}$, children spent on average $29.51 \%$ (SD= $16.90 \%$; range: $1.22 \%-63.76 \%$ ) of their time in MVPA. This translates to approximately 3 minutes of activity at the MVPA intensity level. Boys spent $30.01 \%(\mathrm{SD}=17.27 \%)$ and girls spent $29.01 \%$ ( $\mathrm{SD}=16.69 \%$ ) of the CBAB participating in MVPA. An independent $t$ test indicated that there were no statistically significant differences in MVPA participation $(t=.30, P=.77)$ between boys and girls during the $\mathrm{CBAB}$; therefore, results were analyzed together.

\section{Motor Skill Competency and MVPA}

For locomotor skills, the average raw score on the TGMD-2 was 17.17 ( $\mathrm{SD}=6.52)$. The average raw score for object control skills was slightly higher at $19.98(\mathrm{SD}=5.89)$. Combined, the average total raw score for the TGMD-2 was 37.15 ( $\mathrm{SD}=10.53$ ). Using the TGMD-2 normative data, ${ }^{35}$ the average percentile scores for total TGMD-2 performance for this group was 25.71 ( $\mathrm{SD}=18.70)$. Therefore, on average, this group would be considered at-risk of motor delay, which is classified as being below the 30th percentile. ${ }^{37}$ Specific information about subscale and total scores for boys and girls can be found in Table 1 .

A simple linear regression was calculated to predict percentage of MVPA participation during the CBAB based on total TGMD-2 raw scores; a significant, moderate regression was found $\left(F_{1,97}=\right.$ $11.66, P=.001 ; r=.33)$. Based on this model, percentage of MVPA participation during the $\mathrm{CBAB}$ would increase approximately half a percentage $(\beta=0.53, \mathrm{SE}=0.15)$ for each raw score increase for the TGMD-2.

Table 1 Demographic Information

\begin{tabular}{lccc}
\hline & Boys & Girls & Total \\
\hline $\mathrm{N}$ & 49 & 50 & 99 \\
Age, y & $3.73(0.64)$ & $3.86(0.67)$ & $3.80(0.65)$ \\
\%MVPA during & $30.01(17.27)$ & $29.01(16.69)$ & $29.51(16.90)$ \\
CBAB & & & \\
BMI percentile & $48.67(32.22)$ & $47.49(32.35)$ & $48.07(32.13)$ \\
\%Children & 18.3 & 22.0 & 20.2 \\
overweight/obese & & & \\
LM raw score & $18.31(6.89)$ & $16.06(5.99)$ & $17.17(6.52)$ \\
OC raw score & $22.00(6.91)$ & $18.00(3.81)$ & $19.98(5.89)$ \\
TGMD-2 raw score & $40.31(11.92)$ & $34.06(7.93)$ & $37.15(10.53)$ \\
\hline
\end{tabular}

Abbreviations: BMI, body mass index; $\mathrm{CBAB}$, classroom-based activity break; MVPA, moderate to vigorous physical activity; LM, locomotor, OC, object control; TGMD-2, Test of Gross Motor Development—second edition. Note: Values are presented as mean (SD).
Looking at the subscales separately, there was a positive, weak relationship between locomotor performance and MVPA participation during the $\mathrm{CBAB}\left(F_{1,97}=10.78, r=.32, P<.001\right)$; a similar positive, weak relationship was seen for the object control subscale $\left(F_{1,97}=5.72, r=.24, P=.02\right)$ and MVPA participation during the CBAB.

\section{Weight Classification and MVPA}

The breakdown of weight classification status for this group, according to the appropriate CDC BMI-for-age growth charts, was $7.1 \%$ of students were underweight, $72.7 \%$ were normal weight, $8.1 \%$ were overweight, and $12.1 \%$ were classified as obese. The percentage of overweight or obese girls and boys was $22.0 \%$ and $18.3 \%$, respectively. Average weight for this group was 40.43 pounds with a range between 29.00 and 85.20 pounds.

Using BMI percentiles, we examined the relationship between weight status and participation in MVPA during the $\mathrm{CBAB}$ and found that there was no statistical significant relationship $\left(F_{1,97}=\right.$ 1.78, $r=.13, P=.19)$. This indicates that weight classification status was not associated with MVPA participation during the activity breaks.

\section{Contributing Factors to MVPA in CBAB}

A backward elimination regression was used to determine which factors might explain the greatest variance in MVPA participation during the CBAB. This analysis included the TGMD-2 locomotor subscale, TGMD-2 object control subscale, and BMI percentile. The backward elimination regression indicated that the locomotor subscale was the best predictor for MVPA during the CBAB $\left(F_{1,97}=10.78, P<.001, r=.32\right)$. This indicates that locomotor skill competency accounted for $10 \%$ of the variance for MVPA participation during the CBAB. In addition, MVPA participation percentage during the $\mathrm{CBAB}$ should increase $0.820(\mathrm{SE}=0.250)$ for each raw score point increase in the locomotor subscale of the TGMD-2. Details may be found in Table 2.

\section{Discussion}

This study investigated what factors were associated with MVPA participation during a CBAB in a Head Start preschool population. Mixed results were found based on our hypothesized results. First, we hypothesized that children with higher motor skill competency would participate in more MVPA behaviors. This hypothesis was supported, as a moderate, positive relationship was found between TGMD-2 total raw scores and MVPA participation; on average, this population would qualify for being at-risk for motor delay. Second, we hypothesized that children with higher BMI would participate in less MVPA during these short bouts. Contrary to our hypothesis, no relationship was found between BMI percentile and MVPA, indicating that overweight and obese children performed similar levels of MVPA as normal weight children. Finally, our exploratory aim was to examine what factors may contribute the most to MVPA behaviors in an at-risk group of children. Results showed that locomotor skill performance on the TGMD-2 contributed the most variance to MVPA participation during the CBAB.

A noticeable result of this project was the low levels of MVPA during the $\mathrm{CBAB}$; however, previous research has shown low levels of physical activity in preschool-age children. Shen et $\mathrm{al}^{46}$ found that Head Start preschoolers spend approximately $1 \%$ of their school day in MVPA. Using direct observation throughout the 
Table 2 Backward Elimination Multiple Regression Examining Percentage of MVPA Participation During the Classroom-Based Activity Break

\begin{tabular}{|c|c|c|c|c|c|c|c|}
\hline \multirow[b]{2}{*}{ Variables entered } & \multicolumn{2}{|c|}{$\begin{array}{l}\text { Unstandardized } \\
\text { coefficients }\end{array}$} & \multirow[b]{2}{*}{$t$} & \multirow[b]{2}{*}{ Sig. } & \multicolumn{2}{|c|}{$95 \% \mathrm{Cl}$} & \multirow[b]{2}{*}{$r$} \\
\hline & $\beta$ & SE & & & Lower & Upper & \\
\hline \multicolumn{8}{|l|}{ Step 1} \\
\hline Constant & 14.334 & & 2.198 & .03 & 1.386 & 27.282 & .362 \\
\hline BMI percentile & -0.073 & 0.050 & -1.446 & .15 & -0.173 & 0.027 & \\
\hline OC raw score & 0.342 & 0.306 & 1.118 & .27 & -0.265 & 0.948 & \\
\hline LM raw score & 0.690 & 0.276 & 2.497 & .01 & 0.141 & 1.238 & \\
\hline \multicolumn{8}{|l|}{ Step 2} \\
\hline Constant & 18.845 & & 3.673 & $<.001$ & 8.660 & 29.060 & .345 \\
\hline BMI percentile & -0.073 & 0.050 & -1.452 & .15 & -0.173 & 0.027 & \\
\hline LM raw score & 0.826 & 0.248 & 3.324 & .001 & 0.333 & 1.319 & \\
\hline \multicolumn{8}{|l|}{ Step 3} \\
\hline Constant & 15.426 & & 3.365 & .001 & 6.326 & 24.526 & .316 \\
\hline LM raw score & 0.820 & 0.250 & 3.282 & .001 & 0.324 & 1.316 & \\
\hline
\end{tabular}

Abbreviations: BMI, body mass index; CI, confidence interval; MVPA, moderate to vigorous physical activity; LM, locomotor; OC, object control.

entire preschool day, Pate et $\mathrm{al}^{4}$ found that children engaged in MVPA only $3.4 \%$ of the time and were sedentary $85 \%$ of observations. Wadsworth et $\mathrm{al}^{33}$ found that MVPA accumulated during a 10-minute $\mathrm{CBAB}$ accounted for a significant portion of MVPA throughout the school day, specifically $69 \%$ and $90 \%$ of daily MVPA, from 2 different preschool centers. Therefore, the current project where children spent approximately one third of their time in a structured CBAB may lead to more opportunities for children to accumulate MVPA throughout their time spent in preschool. Alternate opportunities to increase MVPA might include utilizing the structured nature of the $\mathrm{CBAB}$ into a longer physical activity session, such as outdoor play. In addition, increasing the amount of time dedicated to the $\mathrm{CBAB}$ or holding multiple $\mathrm{CBAB}$ sessions throughout the day may result in larger increases in MVPA for this population.

\section{Motor Skill Competence}

Previous research has indicated that preschool-age children with higher FMS competency tends to acquire higher levels of MVPA compared with their less skilled peers. ${ }^{19,20}$ The current research project indicated that there was a moderate relationship between FMS competency and MVPA participation during a short bout of structured physical activity. This was a surprising finding as the average participant in this study was considered at-risk for motor delay based on TGMD-2 normative data. ${ }^{44}$ Low levels of FMS competency have been shown in other studies focusing on Head Start children; Liu et $\mathrm{al}^{47}$ found that Head Start preschoolers perform significantly worse than children not attending Head Start on both fine and gross FMS. Active Start guidelines ${ }^{3}$ recommend that children have competency in a wide range of FMS, which increases a child's capability to engage in diverse movement opportunities. This study's low levels of FMS highlight a need to target these skills in Head Start programs.

Locomotor skills were also the only significant contributor to overall variance in MVPA participation during the CBAB. This finding is perhaps not surprising since locomotor skills require the activation of large muscle groups ${ }^{48}$ and provide a foundation for a range of activities that are needed for physical activity participation. ${ }^{15}$ This finding aligns with previous work that has found locomotor motor skills are positively correlated with physical activity in preschoolers. ${ }^{18,49,50}$ This may be particularly relevant for Head Start populations who have previously been shown to perform worse on locomotor skills than preschool children in private school settings. ${ }^{51}$ Alhassan et $\mathrm{al}^{49}$ found that an intervention targeting locomotor skills significantly reduced sedentary behavior in minority preschool children, which provides insight into the notion that targeted practice of locomotor skills could enhance participation in structured opportunities. The preschool years are a critical time for FMS development to begin to adapt healthy physical activity behaviors.

\section{Weight Classification Status}

One in 5 children in this study were classified as overweight or obese; previous work has indicated that children attending Head Start centers have a higher incidence of overweight and obesity. ${ }^{52}$ We hypothesized that overweight children would not participate in as much physical activity behaviors during the $\mathrm{CBAB}$; however, in reference to weight status, all children performed MVPA similarly in this sample. Short bouts of physical activity might be an ideal way to increase MVPA in overweight and obese preschoolers, particularly in a population that is susceptible to increased obesity rates. Trost et $\mathrm{al}^{7}$ found that overweight boys were significantly less active compared with normal weight peers. Physical activity is a modifiable risk factor that comes with a large number of positive outcomes including healthy weight management. Longitudinal work by Butte et $\mathrm{al}^{12}$ found that MVPA was negatively related to adiposity over 1 year in preschool-age children. Inactivity is a serious concern as research in preschool-age children indicate that overweight children are more at-risk for future adiposity gains due to lack of physical activity participation and engagement. ${ }^{7}$

Sustained teacher-led interventions have been shown to increase levels of physical activity and reduce BMI, highlighting a practical opportunity to continue promoting these behaviors in childcare settings. ${ }^{53}$ Particularly as some evidence indicates that children garner more physical activity during the school day than outside care centers at home. ${ }^{30}$ Sustained activity breaks over 
2 years have shown to decrease BMI in elementary school students, indicating that short breaks may be adequate to elicit long-term benefits. ${ }^{54}$ Short bouts of activity may provide an avenue for targeting overweight and obese children to increase their physical activity behaviors in small increments that may accumulate to make significant gains in total physical activity time in this group.

\section{Limitations}

This study had several limitations that should be considered when generalizing findings to other settings. The intervention was implemented in one preschool Head Start center; thus, characteristics of the school may have influenced results, such as effects influenced by the teachers implementing the intervention and scheduling specific to Head Start centers. Since this population was primarily lowincome African American children, results may be limited in their interpretation to other groups. In addition, a large portion of variance was not accounted for by factors examined in this study; therefore, further work needs to be done to identify other contributors to physical activity in this age group; factors such as self-concept or perceived motor competence may contribute to participation in these physical activities as well as enjoyment. This was a within-subjects research design, where each participant served as their own control; as such, there was no true control group, which is a limitation for the present work. Finally, this was a cross-sectional design and thus cannot infer causation; longitudinal work would be appropriate to further understand this relationship and how these variables would contribute to a preschooler's activity long term. In addition, experimental research is needed to understand if potential increases in MVPA during activity breaks are mediated or moderated by motor skill proficiency in preschoolers.

\section{Conclusions}

To date, this is the first investigation to examine factors that may contribute to MVPA participation in CBAB. Classroom-based activity breaks have been shown to be a viable option to increasing physical activity during the preschool and school day $33,34,55,56$; more work is needed to investigate what factors may be most effective in implementing this form of activity. Results indicated that activity breaks equally elicited MVPA participation from all levels of weight classifications, supporting a viable solution to increasing physical activity in preschoolers. Future research is needed to determine if shorter or longer bouts may elicit similar types of responses in each of these groups. However, results provided evidence for an intervention approach that created opportunities for overweight and normal weight children to equally participate in physical activity.

Another important finding from this study was that locomotor skills (of the variables examined) contributed the most to a child's MVPA participation during an activity break. This is congruent with other research that shows higher FMS competency is associated with more physical activity in children, particularly locomotor skills in this population. The incorporation of more structured opportunities that focus on mastering locomotor skills may be a useful integration to prompt more activity during the school day and could warrant further investigation.

For preschool teachers, CBAB are a cost-effective approach (ie, no equipment is needed) that may be implemented in the classroom which could elicit more MVPA in preschool children throughout the school day. These structured bouts only posed a small time constraint, indicating that they could be implemented multiple times throughout the school day or incorporated into preexisting transitions. Future research investigations could explore issues relating to the amount of education and training needed to provide teachers with appropriate movement strategies and proper motor skill execution (eg, locomotor skills) to assist children in being more active via activity breaks. Thematic lessons could also be created to highlight FMS and physical activity behaviors that could teach preschoolers more about being physically active as well as reinforce different academic concepts (eg, counting, body awareness). In addition, teachers have a large influence on the scheduling and implementation of activities related to physical activity and health; therefore, further investigation into their perceptions toward physical activity, appropriate modeling of desired behaviors, and overall influence on physical activity is imperative. Finally, preschool policies that dictate whether teachers have flexibility to schedule $\mathrm{CBAB}$ are an important area of inquiry. One future research area is whether promoting a longstanding policy change to incorporate CBAB into the preschool day could be an effective way of increasing physical activity behaviors long term.

\section{References}

1. US Department of Health and Human Services. Physical Activity Guidelines for Americans. 2nd ed. Washington, DC: US Department of Health and Human Services; 2018.

2. Jones RA, Hinkley T, Okely AD, Salmon J. Tracking physical activity and sedentary behavior in childhood: a systematic review. Am J Prev Med. 2013;44(6):651-658. PubMed ID: 23683983 doi:10. 1016/j.amepre.2013.03.001

3. National Association for Sport and Physical Education. Active Start: A Statement of Physical Activity Guidelines for Children from Birth to Age 5. 2nd ed. Oxon Hill, MD: AAHPERD Publications; 2009.

4. Pate RR, McIver K, Dowda M, Brown WH, Addy C. Directly observed physical activity levels in preschool children. J Sch Health. 2008;78(8):438-444. PubMed ID: 18651931 doi:10.1111/j.17461561.2008.00327.x

5. Schlechter CR, Rosenkranz RR, Fees BS, Dzeqaltowski DA. Preschool daily patterns of physical activity driven by location and social context. J Sch Health. 2017;87(3):194-199. PubMed ID: 28147455 doi:10.1111/josh.12486

6. Reilly JJ. Physical activity, sedentary behavior and energy balance in the preschool child: opportunities for early obesity prevention. Proc Nutr Soc. 2008;67:317-325. PubMed ID: 18700053 doi:10.1017/ S0029665108008604

7. Trost SG, Sirard JR, Dowda M, Pfeiffer KA, Pate RR. Physical activity in overweight and nonoverweight preschool children. Int $J$ Obes Relat Metab Disord. 2003;27:834-839. PubMed ID: 12821970 doi:10.1038/sj.ijo.0802311

8. te Velde SJ, van Massau F, Uijtdewilligen L, et al. Energy balancerelated behaviours associated with overweight and obesity in preschool children: a systematic review of prospective studies. Obes Rev. 2012;13(suppl 1):56-74. doi:10.1111/j.1467-789X.2011.00960.x

9. Moore LL, Nguyen US, Rothman KJ, Cupples LA, Ellison RC. Preschool physical activity level and change in body fatness in young children. The Framingham Children's Study. Am J Epidemiol. 1995; 142(9):982-988. PubMed ID: 7572980 doi:10.1093/oxfordjournals. aje.a117747

10. Centers for Disease Control and Prevention. Healthy youth! U.S. Department of Health and Human Services Web Site. http://www.cdc. gov/HealthyYouth/index.htm. Updated May 1, 2018. Accessed May 25, 2018. 
11. Meredith-Jones K, Haszard J, Moir C, et al. Physical activity and inactivity trajectories associated with body composition in preschoolers. Int J Obes. 2018;42:1621-1630. doi:10.1038/s41366018-0058-5

12. Butte NF, Puyau MR, Wilson TA, et al. Role of physical activity and sleep duration in growth and body composition of preschool-aged children. Obesity. 2016;24:1328-1335. PubMed ID: 27087679 doi:10.1002/oby.21489

13. Metallinos-Katsaras ES, Freedson PS, Fulton JE, Sherry B. The association between an objective measure of physical activity and weight status in preschoolers. Obesity. 2007;15:686-694. PubMed ID: 17372319 doi:10.1038/oby.2007.571

14. Logan SW, Scrabis-Fletcher K, Modlesky C, Getchell N. The relationship between motor skill proficiency and body mass index in preschool children. Res Q Exerc Sport. 2013;82(3):442-448. doi:10. 1080/02701367.2011.10599776

15. Clark JE, Metcalfe JS. The mountain of motor development: A metaphor. In: JE Clark, JH Humphrey, eds. Motor Development: Research and Review. Vol. 2. Reston, VA: National Association for Sport and Physical Education; 2002:62-95.

16. Gallahue DL, Ozmun JC, Goodway J. Understanding Motor Development: Infants, Children, Adolescents, Adults. 7th ed. New York, NY: McGraw-Hill; 2012.

17. Bayer O, Bolte G, Morlock G, Rücking S, von Kries R. A simple assessment of physical activity is associated with obesity and motor fitness in pre-school children. Public Health Nutr. 2008;12(8):1242-1247. PubMed ID: 18826661 doi:10.1017/ S1368980008003753

18. Robinson LE, Wadsworth DD, Peoples CM. Correlates of school-day physical activity in preschool students. Res Q Exerc Sport. 2012; 83(1):20-26. PubMed ID: 22428408 doi:10.1080/02701367. 2012.10599821

19. Cliff DP, Okely AD, Smith LM, McKeen K. Relationships between fundamental movement skills and objectively measured physical activity in preschool children. Pediatr Exerc Sci. 2009;21:436449. PubMed ID: 20128363 doi:10.1123/pes.21.4.436

20. Robinson LE, Goodway JD. Instructional climates in preschool children who are at-risk. Part 1: object-control skill development. Res Q Exerc Sport. 2009;80(3):533-542. PubMed ID: 19791639

21. Barnett LM, van Beurden E, Morgan PJ, Brooks LO, Beard JR. Childhood motor proficiency as a predictor of adolescent physical activity. J Adolesc Health. 2009;44:252-259. PubMed ID: 19237111 doi:10.1016/j.jadohealth.2008.07.004

22. Lopes VP, Rodrigues LP, Maia JAR, Malina RM. Motor coordination as predictor of physical activity in childhood. Scand J Med Sci Sports. 2011;21:663-669. PubMed ID: 21917017 doi:10.1111/j.1600-0838. 2009.01027.x

23. Venetsanou F, Kambas A. Can motor proficiency in preschool age affect physical activity in adolescence? Pediatr Exerc Sci. 2017;29:254-259. PubMed ID: 27705534 doi:10.1123/pes.20160119

24. Bellows LL, Davies PL, Courtney JB, Gavin WJ, Johnson SL, Boles RE. Motor skill development in low-income, at-risk preschoolers: a community-based longitudinal intervention study. J Sci Med Sport. 2017;20:997-1002. PubMed ID: 28506451 doi:10.1016/j.jsams. 2017.04.003

25. Goodway JD, Branta CF. Influence of a motor skill intervention on fundamental motor skill development of disadvantaged preschool children. Res Q Exerc Sport. 2003;74(1):36-46. PubMed ID: 12659474 doi:10.1080/02701367.2003.10609062

26. Logan SW, Robinson LE, Wilson AE, Lucas WA. Getting the fundamentals of movement: a meta-analysis of the effectiveness of motor skill interventions in children. Child Care Health Dev. 2012;38(3):305-315. PubMed ID: 21880055 doi:10.1111/j.13652214.2011.01307.x

27. Castelli DM, Glowacki E, Barcelona JM, Calvert HG, Hwang J. Active Education: Growing Evidence on Physical Activity and Academic Performance. San Diego, CA: Active Living Research; 2015.

28. Gordon ES, Tucker P, Burke SM, Carron AV. Effectiveness of physical activity interventions for preschoolers: a meta-analysis. Res Q Exerc Sport. 2013;84:287-294. PubMed ID: 24261007 doi:10.1080/02701367.2013.813894

29. Tandon PS, Saelens BE, Copeland KA. A comparison of parent and childcare provider's attitudes and perceptions about preschoolers' physical activity and outdoor time. Child Care Health Dev. 2016;43(5):679-686. PubMed ID: 27891655 doi:10.1111/cch. 12429

30. Hesketh KR, Griffin SJ, van Sluijs EMF. UK preschool-aged children's physical activity levels in childcare and at home: a crosssectional exploration. Int J Behav Nutr Phys Act. 2015;12:123. PubMed ID: 26410252 doi:10.1186/s12966-015-0286-1

31. Alhassan S, Sirard JR, Robinson TR. The effects of increasing outdoor play time on physical activity in Latino preschool children. Int J Pediatr Obes. 2007;13:1-6.

32. Van Cauwenberghe E, De Craemer M, De Decker E, De Bourdeaudhuij I, Cardon G. The impact of a teacher-led structured physical activity session on preschoolers' sedentary and physical activity levels. J Sci Med Sport. 2013;16:422-426. PubMed ID: 23246443 doi:10.1016/j.jsams.2012.11.883

33. Wadsworth DD, Robinson LE, Beckham K, Webster K. Break for physical activity: incorporating classroom-based physical activity breaks into preschools. Early Child Educ J. 2012;39:391-395. doi:10.1007/s10643-011-0478-5

34. Webster EK, Wadsworth DD, Robinson LE. Preschoolers' time ontask and physical activity during a classroom activity break. Pediatr Exerc Sci. 2015;27(1):160-167. PubMed ID: 25249496 doi:10.1123/ pes.2014-0006

35. Brofenbrenner U. Toward an experimental ecology of human development. Am Psychol. 1977;32:513-531. doi:10.1037/0003-066X.32. 7.513

36. Brofenbrenner U. The Ecology of Human Development. Cambridge, MA: Harvard University Press; 1979.

37. Alhassan S, St. Laurent CW, Burkart S, Greever CJ, Ahmadi MN. Feasibility of integrating physical activity into early education learning standards on preschooler's physical activity levels. J Phys Act Health. 2019;16:101-107. PubMed ID: 30626270 doi:10.1123/jpah. 2017-0628

38. Pate RR, Brown WH, Pfeiffer KA, et al. An intervention to increase physical activity in children: a randomized controlled trial with 4-year-olds in preschools. Am J Prev Med. 2016;51(1):12-22. PubMed ID: 26803357 doi:10.1016/j.amepre.2015.12.003

39. Määttä S, Ray C, Roos G, Roos E. Applying a socioecological model to understand preschool children's sedentary behaviors from the viewpoints of parents and preschool personnel. Early Child Educ J. 2016;44:491-502. doi:10.1007/s10643-015-0737-y

40. Campbell DT, Stanley JC. Experimental and Quasi-Experimental Designs for Research. Boston, MA: Houghton Mifflin Company; 1959.

41. Kuczmarski R, Ogden C, Guo S. CDC Growth Charts for the United States: Methods and Development. Atlanta, GA: National Center for Health Statistics; 2000.

42. Pfeiffer KA, McIver KL, Dowda M, Almeida MJ, Pate RR. Validation and calibration of the Actical accelerometer in preschool 
children. Med Sci Sports Exerc. 2006;38(1):152-157. PubMed ID: 16394968 doi:10.1249/01.mss.0000183219.44127.e7

43. Cliff DP, Reilly JJ, Okely AD. Methodological considerations in using accelerometers to assess habitual physical activity in children aged 0-5 years. J Sci Med Sport. 2009;12:557-567. PubMed ID: 19147404 doi:10.1016/j.jsams.2008.10.008

44. Ulrich DA. The Test of Gross Motor Development. 2nd ed. Austin, TX: PRO-ED; 2000.

45. Pedhazur EJ. Multiple Regression in Behavioral Research: Explanatin and Prediction. 3rd ed. Belmont, CA: Wadsworth Thomson Learning; 1997.

46. Shen B, Reinhart-Lee T, Janisse H, Brogan K, Danford C, Jen K-LC. African American preschool children's physical activity levels in Head Start. Res Q Exerc Sport. 2012;83(2):168-174. PubMed ID: 22808702 doi:10.1080/02701367.2012.10599847

47. Liu T, Hamilton M, Smith S. Motor proficiency of the Head Start and typically developing children on MABC-2. J Child Adolesc Behav. 2015;3:198.

48. Haywood KM, Getchell N. Lifespan Motor Development. 6th ed. Champaign, IL: Human Kinetics; 2014.

49. Alhassan S, Nwaokelemeh O, Ghazarian M, Roberts J, Mendoza A, Shitole S. Effects of locomotor skill program on minority preschoolers' physical activity levels. Pediatr Exerc Sci. 2012;24:435-449. PubMed ID: 22971559 doi:10.1123/pes.24.3.435

50. Hardy LL, King L, Farrell L, Macniven R, Howlett S. Fundamental movement skills among Australian preschool children. J Sci Med
Sport. 2010;13(5):503-508. PubMed ID: 19850520 doi:10.1016/j. jsams.2009.05.010

51. Chow BC, Louie LHT. Difference in children's gross motor skills between two types of preschools. Percept Mot Skills. 2013;116(1): 253-261. PubMed ID: 23829151 doi:10.2466/25.06.10.PMS.116.1. 253-261

52. Worobey J, Worobey HS, Adler AL. Diet, activity, and BMI in preschool-aged children: differences across settings. Ecol Food Nutr. 2005;44(6):455-466. doi:10.1080/03670240500348797

53. Goldfield GS, Harvey ALJ, Grattan KP, et al. Effects of child care intervention on physical activity and body composition. Am J Prev Med. 2016;51(2):225-231. PubMed ID: 27180030 doi:10.1016/j. amepre.2016.03.024

54. Donnelly JW, Greene JL, Gibson CA, et al. Physical Activity Across the Curriculum (PAAC): a randomized controlled trial to promote physical activity and diminish overweight and obesity in elementary school children. Prev Med. 2009;49:336-341. PubMed ID: 19665037 doi:10.1016/j.ypmed.2009.07.022

55. Mahar MT, Murphy SK, Rowe DA, Golden JA, Shields T, Raedeke TD. Effects of a classroom-based program on physical activity and on-task behavior. Med Sci Sports Exerc. 2006; 38(12):2086-2094. PubMed ID: 17146314 doi:10.1249/01.mss. 0000235359.16685.a3

56. Whitt-Glover M, Porter A, Yancey T. Do Short Physical Activity Breaks in Classrooms Work? A Research Brief Presenation. Princeton, NJ: Active Living Research; 2013. 